\title{
ANALISIS SPASIAL DATA JARINGAN INTERNET SERVICE PROVIDER DI KECAMATAN SUNGAI PINANG KOTA SAMARINDA BERBASIS MOBILE
}

\author{
Edy Budiman \\ edy.budiman@ymail.com \\ Teknik Informatika Universitas Mulawarman
}

\begin{abstract}
Abstrak
Banyak faktor yang dapat mempengaruhi kualitas jaringan bagi penyedia Internet Service Provider (ISP), turunnya nilai throughput dan menaikkan nilai delay, banyaknya ISP, besarnya delay jaringan, banyaknya bangunan/pemukiman tempat mengakses layanan internet dapat menyebabkan adanya paket data yang hilang (packet loss) pada saat pentransmisian. Penelitian ini bertujuan untuk menganalisis spasial jaringan internet dan penyedia Internet Service Provider (ISP) dengan data spasial; Titik lokasi pengukuran, Waktu pengukuran, Besar nilai paket data, dan Operator seluler (ISP) dengan sampel objek pada Kecamatan Sungai Pinang, Kota Samarinda Kalimantan Timur. Metode penelitian menggunakan Analisis Spasial Exploratory dan analisis Spasial Confirmatory. Metode pengumpulan data dengan studi lapangan pengukuran langsung dan studi literatur dengan mengacu standard TIPHON (Telecommunications and Internet Protocol Harmonization Over Networks). Hasil analisis data pengukuran bahwa besarnya nilai jitter, delay, throughput pada provider yang ada di objek penelitian masih sangat tinggi. Indeks pengukuran berdasarkan standar dari TIPHON terhadap parameter-parameter QoS, bahwa kualitas pelayanan jaringan internet berbasis seluler di Kecamatan Sungai Pinang Kota Samarinda dalam kategori jelek, sedang dan sangat bagus.
\end{abstract}

Kata kunci: data, spasial, ISP, QoS, jaringan.

ILKOM Jurnal Ilmiah work is licensed under a CCA-SA 4.0 International License.

\section{Pendahuluan}

Layanan komunikasi data melalui jaringan seluler atau secara umum jaringan nirkabel yang menjadi ciri komunikasi modern saat ini yaitu komunikasi tanpa batas (seamless communication). Untuk dapat berkomunikasi maka diperlukan jarigan seluler yang memiliki kecepatan akses tinggi, hal ini merupakan suatu alasan untuk dikembangkannya teknologi seluler dengan perkembangan EDGE, GPRS, 3G hingga High Speed Downlink Packet Access (HSDPA). Contoh dari layanan ini adalah layanan akses internet, sistem informasi basis data, online game dan lain sebagainya.

Teknologi pada penggunaan layanan internet, khususnya jaringan seluler yang berkembang dengan pesat saat ini memberikan kepuasan tersendiri bagi pengguna seluler pendukung layanan internet. Dengan berkembangnya jaringan seluler juga memberikan peluang bagi para perusahaan telekomunikasi untuk bersaing dalam membangun sebuah Internet Service Provider (ISP). Berbagai layanan yang dapat ditawarkan sehingga melahirkan kompetitor-kompetitor baru yang menyebabkan kian turunnya nilai pendapatan perusahaan per-konsumen (ARPU, Average Revenue Per User). Dengan adanya hal ini, tidak diragukan lagi para penyedia layanan tersebut dituntut dapat berupaya kreatif dan inovatif. Untuk dapat menjaga kelayakan layanan internet, penyedia Internet Service Provider (ISP) diupayakan dapat menyediakan Quality of Service (QoS) yang bagus pada trafik jaringannya. Dengan menyediakan Quality of Service (QoS) tersebut pada pelaksanaannya membutuhkan tolak ukur terhadap performansi jaringan seluler yang digunakan dengan beragam parameter jaringan, dengan standar yang dianggap berkualitas [5].

Banyak faktor yang dapat mempengaruhi kualitas jaringan (network quality) bagi penyedia Internet Service Provider (ISP), misalnya turunnya nilai throughput dan menaikkan nilai delay, sehingga menurunkan kualitas layanan internet. Banyaknya Provider (ISP) dapat menyebabkan meningkatkan besarnya delay jaringan dari banyaknya paket data yang menunggu/mengantri untuk dapat dikirimkan. Banyaknya bangunan ataupun gedung dan dimana pemukiman tempat mengakses layanan internet juga dapat menyebabkan terganggunya proses propagasi gelombang atau yang biasa disebut redaman propagasi. Redaman propagasi menyebabkan adanya paket data yang hilang (packet loss) pada saat pentransmisian yang sangat berpengaruh terhadap besarnya nilai throughput [6]. 
Telah banyak penelitian dan sistem yang dikembangkan untuk mengetahui performansi jaringan nirkabel khususnya jaringan telekomunikasi seluler. Beberapa studi telah dilakukan untuk beragam variasi protokol jaringan: HSDPA (Teuku Yuliar Arif, UNSYIAH Aceh. 2010), EDGE (Sigit Haryadi dan Arie Wibowo W, ITB. 2010), GPRS (Yati Rodiati, ITB. 2010), CDMA (Tria Sinta, UNILA. 2006), Analisis Quality of Service (QOS) Pengukuran Jaringan Seluler Kota Samarinda (T Marthen Dkk. 2015).

Penelitian sebelumnya lebih berfokus pada perbandingan dan kualitas Quality of Service (QOS) jaringan sedangkan penelitian ini berfokus pada analisis spasial dan data spasial jaringan internet provider yang tersedia pada objek penelitian.

\section{Landasan Teori}

\subsection{Analisis Spasial}

Analisis spasial merupakan sekumpulan metoda untuk menemukan dan menggambarkan tingkatan/ pola dari sebuah fenomena spasial, sehingga dapat dimengerti dengan lebih baik. Dengan melakukan analisis spasial, diharapkan muncul infomasi baru yang dapat digunakan sebagai dasar pengambilan keputusan di bidang yang dikaji. Metoda yang digunakan sangat bervariasi, mulai observasi visual sampai ke pemanfaatan matematika/statistik terapan [3].

Ada banyak metoda dalam melakukan Analisis Spasial. Berdasarkan Tujuannya, secara garis besar dapat dibedakan menjadi 2 macam [4]:

1) Analisis Spasial Exploratory, digunakan untuk mendeteksi adanya pola khusus pada sebuah fenomena spasial serta untuk menyusun sebuah hipotesa penelitian. Metoda ini sangat berguna ketika hal yang diteliti merupakan sesuatu hal yang baru, dimana peneliti tidak/ belum memiliki banyak pengetahuan tentang fenomena spasial yang sedang diamati.

2) Analisis Spasial Confirmatory, Dilakukan untuk mengonfirmasi hipotesa penelitian. Metoda ini sangat berguna ketika peneliti sudah memiliki cukup banyak informasi tentang fenomena spasial yang sedang diamati, sehingga hipotesa yang sudah ada dapat diuji keabsahannya.

Pengertian ringkas menyatakan bahwa analisis spasial merupakan:

a. Sekumpulan teknik untuk menganalisis data spasial

b. Sekumpulan teknik yang hasil-hasilnya sangat bergantung pada lokasi objek yang bersangkutan (yang sedang dianalisis)

c. Sekumpulan teknik yang memerlukan akses baik terhadap lokasi objek maupun atribut-atributnya.

\subsection{Data Spasial}

Data spasial mempunyai pengertian sebagai suatu data yang mengacu pada posisi, obyek, dan hubungan diantaranya dalam ruang bumi. Data spasial merupakan salah satu item dari informasi, dimana didalamnya terdapat informasi mengenai bumi termasuk permukaan bumi, dibawah permukaan bumi, perairan, kelautan dan bawah atmosfir [1]. Data spasial dan informasi turunannya digunakan untuk menentukan posisi dari identifikasi suatu elemen di permukaan bumi. Lebih lanjut lagi Mapping Science Committee [1], menerangkan mengenai pentingnya peranan posisi lokasi yaitu,

1) Pengetahuan mengenai lokasi dari suatu aktifitas memungkinkan hubungannya dengan aktifiktas lain atau elemen lain dalam daerah yang sama atau lokasi yang berdekatan dan

2) Lokasi memungkinkan diperhitungkan nya jarak, pembuatan peta, memberikan arahan dalam membuat keputusan spasial yang bersifat kompleks.

Karakteristik utama dari data spasial adalah bagaimana mengumpulkannya dan memeliharanya untuk berbagai kepentingan. Selain itu juga ditujukan sebagai salah satu elemen yang kritis dalam melaksanakan pembangunan sosial ekonomi secara berkelanjutan dan pengelolaan lingkungan. Berdasarkan perkiraan hampir lebih dari 80 \% informasi mengenai bumi berhubungan dengan informasi spasial [3].

Pada dasarnya terdapat dua permalahan utama yang terjadi pada saat ini dalam pembangunan data spasial [4]. Pertama adalah "ledakan" informasi, dimana informasi tersebut diperlukan dalam perkembangan waktu yang terjadi. Hal ini sangatlah bergantung pada perkembangan yang cepat dalam proses pengambilan dan perekaman data spasial. Sedangkan yang kedua adalah terbatasnya dan sulitnya melakukan akses dan mendapatkan informasi spasial dari berbagai macam sumber data yang tersedia. Konsekuensi yang terjadi terdapat kebutuhan yang sangat mendesak untuk memecahkan permasalahan tersebut, yaitu dengan melakukan konsep berbagi pakai data, integrasi dari aplikasi yang berbeda dan mengurangi duplikasi data dan minimalisasi biaya pengeluaran yang terjadi.

Terkait dengan penelitian ini, yang menjadi data spasial jaringan internet adalah data lokasi atau penentuan titik koordinat pengambilan pengukuran jaringan internet dan layanan (service) provider yang tersedia di area tersebut. 


\subsection{Profil Kecamatan Sungai Pinang}

Samarinda sebagai ibukota Kalimantan Timur saat ini terbagi ke dalam 10 (sepuluh) kecamatan. Salah satu kecamatannya adalah Kecamatan Sungai Pinang dengan komposisi 5 (lima) kelurahan dan luas wilayah $34,16 \mathrm{Km} 2$. Secara geografis, Kecamatan Sungai Pinang berbatasan langsung dengan 4 (empat) kecamatan, diantaranya: sebelah utara berbatasan dengan Kec. Samarinda Utara, sebelah timur dan selatan berbatasan dengan Kec. Samarinda llir yang membatasinya serta di sebelah barat berbatasan dengan Kec. Samarinda Ulu [2].

Pada tahun 2010, kelurahan di kecamatan Samarinda Utara berjumlah 11 kelurahan, tetapi sejak tahun 2011 terpecah menjadi 3 Kecamatan (Kecamatan Samarinda Utara, Kecamatan Sungai Pinang dan Kecamatan Samarinda llir) oleh sebab itulah Kecamatan Sungai Pinang sekarang definitive memiliki 5 Kelurahan setelah pemekaran [2].

Penduduk Kecamatan Sungai Pinang dari tahun 2013-2014 mengalami peningkatan. Begitu pula dengan perkembangan penduduk menurut jenis kelamin dari segi Rasio juga, terjadi peningkatan dari tahunnsebelumnya. Kecamatan Sungai Pinang merupakan salah satu kecamatan terpadat di Kota Samarinda. Pada tahun 2014 terdapat peningkatan jumlah penduduk di Kecamatan Sungai Pinang dibandingkan dengan tahun sebelumnya. Penduduk yang mengalami peningkatan yang cukup pesat dibandingkan dengan kelurahan lain berada di Kelurahan Mugirejo yaitu dari 15.533 jiwa meningkat menjadi 18.843 jiwa di Tahun 2014 [2].

\section{Metode}

\subsection{Jenis Data}

a) Data Primer

Data primer pada penelitian ini adalah data hasil pengukuran yang diambil secara langsung ketika melakukan pengujian atau pengukuran, yaitu delay, throughput dan jitter.

b) Data Sekunder

Data sekunder pada penelitian ini adalah data yang standar atau ketentuan yang telah ditetapkan tanpa melalui proses pengukuran, yaitu data monografi di Kecamatan Sungai Pinang, Kota Samarinda yang digunakan sebagai data awal untuk menentukan titik lokasi pengukuran saat akan melaksanakan kegiatan penelitian.

\subsection{Variabel penelitian}

Teknologi jaringan seluler yang berkembang dengan pesat saat ini memberikan kepuasan tersendiri bagi pengguna seluler pendukung akses internet. Berkembangnya teknologi jaringan seluler juga memberikan peluang bagi para perusahaan telekomunikasi untuk bersaing dalam membangun sebuah Internet Service Provider (ISP).

Ruang lingkup dalam penelitian ini berfokus pada data spasial dan analisis spasial kondisi jaringan ISP pada Kecamatan Sungai Pinang, Kota Samarinda dengan data:

1) Titik lokasi pengukuran.

2) Waktu pengukuran

3) Besar nilai paket data

4) Operator seluler (ISP)

\subsection{Metode Pengumpulan Data}

3.3.1. Studi Lapangan: dengan melakukan pengukurab langsung ke lokasi pengujian. Alat yang digunakan dalam pengumpulan data 1 (satu) unit telepon seluler (client) dan 1 (satu) unit laptop (server) dengan menggunakan aplikasi pengukuran QoS yang dikembangkan menggunakan platform android berbasis seluler dan Location Test berbasis Android serta aplikasi Voiptester yang dapat diinstal melalui Play Store.

3.3.2. Studi Literatur: Studi literatur yaitu dengan mengumpulkan data objek penelitian berupa referensi (buku dan jurnal) untuk mengukur kualitas layanan jaringan seluler berdasar pada standar TIPHON (Telecommunications and Internet Protocol Harmonization Over Networks). 


\subsection{Arsitektur Sistem}

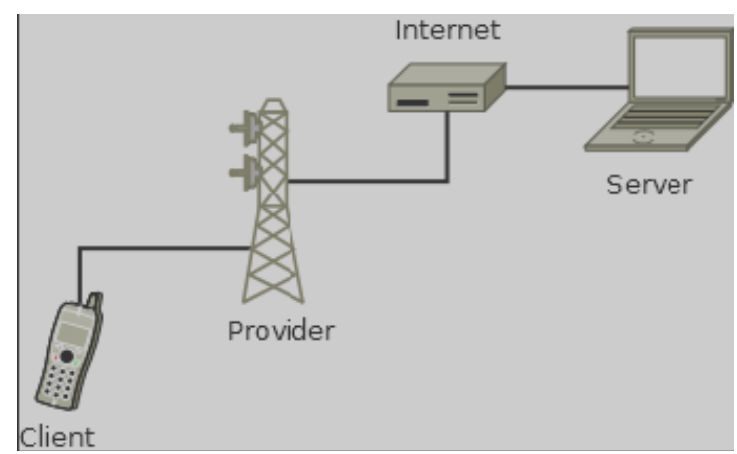

Gambar 1. Arsitektur sistem

\subsection{Deskripsi Rinci Kebutuhan Sistem}

Kebutuhan antarmuka eksternal Antarmuka pemakai Sistem ini dikembangkan dalam bentuk web grafis dalam ukuran tampilan maksimal 1280 x 1024 Pixel dengan 32 Bit Color Quality.

1) Antar muka perangkat keras

Kebutuhan minimum perangkat keras yang dapat digunakan: 1 set komputer PC IBM Compatible dengan memory $2 \mathrm{~GB}$, monitor VGA yang menampilkan resolusi minimal 1024 × 600 pixel.

2) Antarmuka perangkat lunak: Sistem Operasi Windows 7 dan Browser Internet, Android Studio/Eclipse IDE for Java, Location Test dan VoipTester berbasis Android

\subsection{Metode analisis data}

\section{a. Analisis data spasial}

Kualitas layanan bagi penyedia layanan adalah tingkat baik buruknya suatu produk yang dihasilkan dalam memberikan layanan sesuai dengan yang diharapkan pengguna. Tingkat kualitas layanan jaringan seluler yang diharapkan adalah setiap nilai paket yang terkirim sama dengan nilai paket yang dikirim dengan nilai delay seminimal mungkin, sedangkan bagi pengguna, kualitas layanan berarti tingkat kepuasan dalam mempergunakan suatu layanan.

Pengukuran akan dilakukan 4 (empat) sesi tes, dan berikut teori dari masing-masing tes:

1) Delay Test (Latency Test): Delay test (latency test) digunakan untuk menghitung waktu delay saluran uplink dan downlink sebagai efek dari nilai paket. Sejumlah nilai paket dengan ukuran tertentu akan dikirimkan dari client ke server dengan interval waktu yang tetap, lalu oleh server dikembalikan lagi ke client.

Berdasarkan standar TIPHON [6], besarnya delay dapat diklasifikasikan sebagai berikut:

Tabel 1. Tabel Delay (Latency)

\begin{tabular}{llc}
\hline \multicolumn{1}{c}{$\begin{array}{l}\text { Kategori } \\
\text { Latency }\end{array}$} & \multicolumn{1}{c}{ Besar delay } & Indeks \\
\hline Sangat Bagus & $<150 \mathrm{~ms}$ & 4 \\
Bagus & $150 \mathrm{~s} / \mathrm{d} \mathrm{300} \mathrm{ms}$ & 3 \\
Sedang & $300 \mathrm{~s} / \mathrm{d} \mathrm{450} \mathrm{ms}$ & 2 \\
Jelek & $>450 \mathrm{~ms}$ & 1 \\
\hline
\end{tabular}

2) Throughput Test: Throughput test digunakan untuk menghitung jumlah bit yang dapat dilewatkan saluran uplink dan downlink per satuan waktu (detik). Nilai throughput diklasifikasikan sebagai berikut [6]:

Tabel 2. Tabel Throughput

\begin{tabular}{llc}
\hline \multicolumn{1}{c}{ Kategori } & \multicolumn{1}{c}{$\begin{array}{c}\text { Besar } \\
\text { Throughput }\end{array}$} & Indeks \\
\hline Terbaik & $<2.1 \mathrm{mbps}$ & 4 \\
Lebih Baik & $1.2-2.1 \mathrm{mbps}$ & 3 \\
Baik & $0.7-1.2 \mathrm{mbps}$ & 2 \\
Cukup Baik & $0.338-0.7$ & 1 \\
& mbps $-0.338 \mathrm{mbps}$ & \\
Buruk & $0-0.0$ \\
\hline
\end{tabular}


3) Jitter: Jitter akan menurunkan kinerja jaringan ketika nilainya besar dan juga nilai delay-nya besar[6]. Jitter merupakan variasi dari delay. Ketika nilai jitter besar, sedangkan nilai delay-nya kecil maka kinerja jaringan tidak bisa dikatakan jelek karena besarnya nilai jitter dapat dikompensasikan dengan nilai delay yang kecil.Besarnya jitter dapat diklasifikasikan :

Tabel 3. Klasifikasi kategori Jitter

\begin{tabular}{llc}
\hline \multicolumn{1}{c}{ Kategori Jitter } & \multicolumn{1}{c}{ Peak Jitter } & Indeks \\
\hline Sangat Bagus & $0 \mathrm{~ms}$ & 4 \\
Bagus & $0-75 \mathrm{~ms}$ & 3 \\
Sedang & $75-125 \mathrm{~ms}$ & 2 \\
Jelek & $125-225 \mathrm{~ms}$ & 1 \\
\hline
\end{tabular}

4) Titik Lokasi Pengukuran : Penentuan titik lokasi pengukuran adalah yang disarankan oleh pihak Kecamatan Sungai Pinang, Kota Samarinda disesuaikan dengan beberapa faktor, antara lain :

a. 4 (empat) wilayah Kelurahan yang berbeda.

b. Wilayah Kelurahan dipilih berdasarkan kepadatan penduduk terbanyak [3], yaitu :

1) Kel. Sungai Pinang Dalam (39.838 jiwa)

2) Kelurahan Temindung Permai (17.898 jiwa)

3) Kelurahan Mugirejo (15.533 jiwa)

4) Kelurahan Gunung Lingai (10.125 jiwa)

c. Titik lokasi pengukuran ditentukan pada area yang terlihat berpeluang bisnis atau yang termasuk area sekolah di Kelurahan terpilih.

\section{Hasil}

\subsection{Pengukuran Data Spasial}

\section{a. Tes Titik Lokasi Pengukuran}

Tes titik lokasi pengukuran menggunakan aplikasi Location Test berbasis Android yang dapat diinstal melalui Play Store. Berikut contoh tes titik lokasi pengukuran pada Gambar 3.
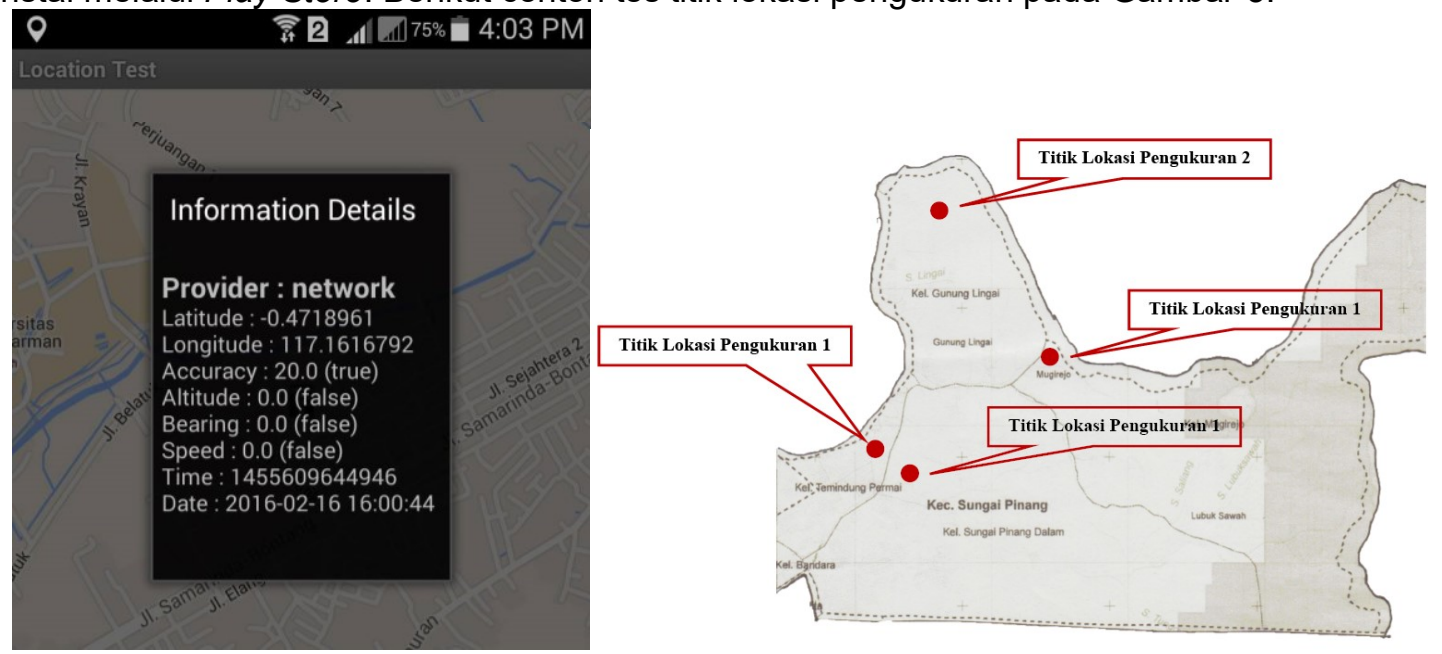

Tabel titik lokasi pengukuran:

Gambar 2. Data Spasial titik lokasi pengukuran

Tabel 4. Data spasial titik lokasi pengukuran

\begin{tabular}{lcc}
\hline \multicolumn{1}{c}{ Titik Lokasi } & Latitude & Longitude \\
\hline JI. D.I Pandjaitan & -0.4686674 & 117.1695521 \\
JI. Gn. Lingai & -0.4610484 & 117.1713399 \\
Jl. Mugirejo & -0.4651562 & 117.1838059 \\
Jl. Bukit Alaya & -0.4633522 & 117.1771958 \\
\hline
\end{tabular}

\section{b. Tes Jaringan}

Tes jaringan pada titik lokasi pengukuran menggunakan aplikasi Voiptester berbasis Android yang dapat diinstal melalui Play Store. 


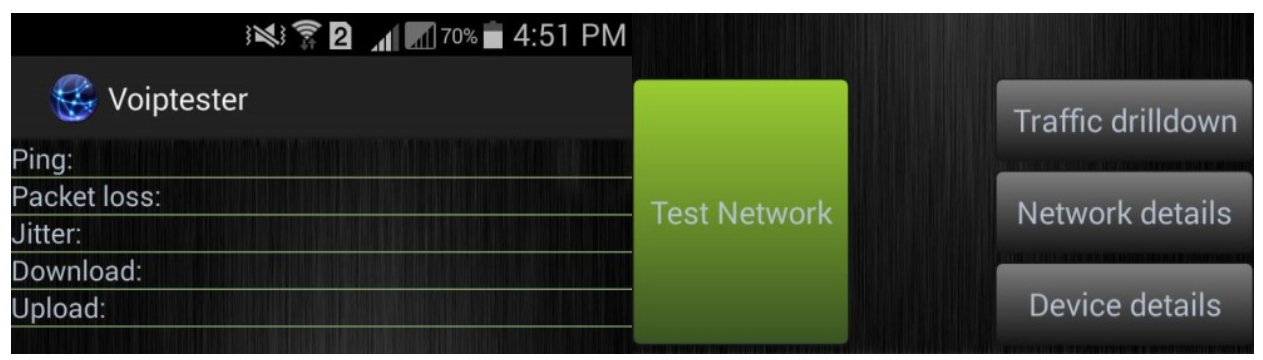

Gambar 3. Aplikasi Voiptester jaringan internet

Menu Test Network digunakan untuk memanggil data tes jaringan pada area sekitar titik lokasi pengukuran. Setelah melakukan tes jaringan, data tes jaringan dapat dilihat pada Network Details.

Pada detail TCP/IP catat IP Server, Server Location, Public IP, Local IP, Network Mask, Network DNS 1, Network DNS 2 dan Network Gateway. Pada detail MOBILE catat Operator dan Radio Technology.

\section{c. Tes Pengiriman Paket Data}

Data pengukuran adalah semua rekapan data mengenai isi database dari kegiatan pengukuran pada tes pengiriman paket data.

\begin{tabular}{|l|}
\hline P.IIl \\
\hline Socket Client \\
\hline IP Server: \\
\hline Ukuran Data yang dikirim satuan byte \\
$(10-1000000):$ \\
\hline 500 \\
Jumlah Iterasi (max 100): 10 \\
Kirim Delay in milli-detik (max 5000): \\
Provider Jaringan * Telkomsel \\
Lokasi Test Client: \\
\hline
\end{tabular}

Gambar 4. Aplikasi pengukuran pengiriman data

Pengukuran data jaringa dilakukan tes sebanyak 10 kali pengujian dengan waktu, besar paket, lokasi dan jenis provider yang ada di lokasi pengujian. Berikut contoh data hasil pengukuran data jaringan.
Nama ISP : Provider A
Waktu : 08.00 Wita (pagi)
Lokasi Tes : II. DI Pandjaitan
Paket kirim : $: 500$ byte

Tabel 5. Pengiriman paket data provider $\mathrm{A}$

\begin{tabular}{|c|c|c|c|c|c|c|}
\hline & IdTes & Urlt & $\bar{U} \mathrm{D} / \mathrm{L}$ & $\overline{D \_D / L}$ & $\bar{U}$ U_T & D_T \\
\hline & SG15A29F36 & 1 & 2254 & 572 & 1774 & 6993 \\
\hline & SG15A29F36 & 2 & 1742 & 1250 & 2296 & 3200 \\
\hline & SG15A29F36 & 3 & 963 & 278 & 4153 & 14388 \\
\hline Waktu & $\begin{array}{l}\text { : Provider B } \\
: 08.00 \text { Wita (pagi) }\end{array}$ & & $\begin{array}{l}\text { Lokasi } \\
\text { Paket }\end{array}$ & & $\begin{array}{l}\text { JI. DI } \\
500 \mathrm{~b}\end{array}$ & ljai \\
\hline
\end{tabular}

Tabel 6. Pengiriman paket data provider B

\begin{tabular}{cccccc}
\hline IdTes & Urlt & U_D/L & D_D/L & U_T & D_T \\
\hline SG15A29F38 & 1 & 701 & 555 & 5706 & 7207 \\
SG15A29F38 & 2 & 1265 & 224 & 3162 & 17857 \\
SG15A29F38 & 3 & 683 & 507 & 5856 & 7889 \\
\hline Lokasi Tes & \multicolumn{3}{c}{ IJ. DI Pandjaitan } \\
O Wita (pagi) & \multicolumn{5}{c}{ Paket kirim byte }
\end{tabular}

Nama ISP : Provider C

Waktu $\quad$ :08.00 Wita (pagi)

Lokasi Tes : : Jl. DI Pandjaitan 
Tabel 7. Pengiriman paket data provider $\mathrm{C}$

\begin{tabular}{cccccc}
\hline IdTes & Urlt & U_D/L & D_D/L & U_T & D_T \\
\hline SG15A29G18 & 1 & 564 & 413 & 7092 & 9685 \\
SG15A29G18 & 2 & 876 & 164 & 4566 & 24390 \\
SG15A29G18 & 3 & 467 & 1741 & 8565 & 2297 \\
\hline
\end{tabular}

Keterangan:
IdTes : Kode Tes
Urlt : Urutan Iterasi
U D/L : Uplink Delay/Latency
D_D/L : Downlink Delay/Latency
U_T : Uplink Throughput $D_{-}^{-} T$ : Downlink Throughput

\subsection{Hasil Analisis Data Spasial}

Data pengukuran di analisis dengan mencari indeks yang adalah hasil rata-rata dari setiap uplink delay/latency, downlink delay/latency, uplink throughput, downlink throughput dan jitter pada tes pengiriman paket data.

Waktu: Pagi Operator: ISP A

Tabel 8. Rata-rat hasil pengiriman data per lokasi

\begin{tabular}{ccclcl}
\hline $\begin{array}{c}\text { Nilai paket } \\
\text { (byte) }\end{array}$ & $\begin{array}{c}\text { Jenis } \\
\text { data }\end{array}$ & $\begin{array}{c}\text { Lokasi } \\
\text { /Titik 1 }\end{array}$ & $\begin{array}{l}\text { Lokasi } \\
\text { /Titik 2 }\end{array}$ & $\begin{array}{l}\text { Lokasi } \\
\text { /Titik 3 }\end{array}$ & $\begin{array}{l}\text { Lokasi } \\
\text { /Titik 4 }\end{array}$ \\
\hline \multirow{2}{*}{500} & U_D/L & 2276,33 & 1962 & 1744,67 & 1803 \\
& D_D/L & 1048,67 & 609,67 & 1335,33 & 614,33 \\
& U_T & 2500 & 2326,33 & 2558,67 & 2537,67 \\
& D_T & 1048,67 & 609,67 & 1335,33 & 614,34 \\
& Jitter & 1597 & 763 & 1459,33 & 560,67 \\
10000 & U_D/L & 8646,67 & 14554,3 & 6960,67 & 8161 \\
& D_D/L & 3362,67 & 10864,3 & 2566,67 & 4370,67 \\
& U_T & 12073,3 & 7605,67 & 12932 & 12805,3 \\
& D_T & 3362,67 & 10864,3 & 2566,67 & 4370,67 \\
& Jitter & 3282 & 8604,3 & 2137 & 5291,67 \\
\hline
\end{tabular}

Dari tabel analisis data pengukuran diatas dapat diketahui bahwa besarnya nilai jitter, delay dan throughput pada tiga provider yang ada di objek penelitian masih sangat tinggi. Hasil analisis data pengukuran diatas dilakukan pada saat pagi, siang dan malam hari dengan titik lokasi yang berbedabeda. Dari tabel hasil analisis diatas dapat dibuat indeks pengukuran seperti dibawah

Tabel 9. Indeks Pengukuran Provider A

\begin{tabular}{cllcl}
\hline Besar Paket & \multicolumn{1}{c}{ Jenis Data } & Rata-Rata & Indeks & Kategori \\
\hline \multirow{5}{*}{500} & Jitter & 435.5 & 1 & jelek \\
& Up_average & 1756.6 & 1 & jelek \\
& Down_average & 579.9 & 1 & jelek \\
& Tup_average & 2495.7 & 4 & Sangat bagus \\
& Tdown_average & 9637.5 & 4 & Sangat bagus \\
\multirow{5}{*}{10000} & Jitter & 1814.8 & 1 & jelek \\
& Up_average & 7052.8 & 1 & jelek \\
& Down_average & 2467.2 & 1 & jelek \\
& Tup_average & 13037.4 & 4 & Sangat bagus \\
& Tdown_average & 42803.3 & 4 & Sangat bagus \\
\hline
\end{tabular}

Tabel 10. Indeks Pengukuran Provider B

\begin{tabular}{clrcc}
\hline Besar Paket & Jenis Data & Rata-Rata & Indeks & Kategori \\
\hline \multirow{5}{5}{500} & Jitter & 464.1665 & 1 & jelek \\
& Up_average & 1393.5 & 1 & jelek \\
& Down_average & 669.6665 & 1 & jelek \\
\hline
\end{tabular}


ILKOM Jurnal Ilmiah Volume 8 Nomor 1 (April 2016)

\begin{tabular}{llrrl}
\hline \multirow{4}{*}{10000} & Tup_average & 3711.1668 & 4 & Sangat bagus \\
& Tdown_average & 7540.1665 & & jelek \\
& Jitter & 3837.5825 & 1 & jelek \\
& Up_average & 7382.8333 & 1 & jelek \\
& Down_average & 4982.99 & 1 & jelek \\
& Tup_average & 19028.333 & 4 & Sangat bagus \\
& Tdown_average & 28773.498 & 4 & Sangat bagus \\
\hline
\end{tabular}

Tabel 11. Indeks Pengukuran Provider C

\begin{tabular}{cllcc}
\hline Besar Paket & Jenis Data & Rata-Rata & Indeks & Kategori \\
\hline \multirow{5}{*}{500} & Jitter & 367.58333 & 1 & jelek \\
& Up_average & 1608.4165 & 1 & jelek \\
& Down_average & 433.75 & 2 & sedang \\
& Tup_average & 5658 & 4 & Sangat bagus \\
& Tdown_average & 16154.083 & 4 & Sangat bagus \\
10000 & Jitter & 2850.4175 & 1 & jelek \\
& Up_average & 5934.0833 & 1 & jelek \\
& Down_average & 4498.0025 & 1 & jelek \\
& Tup_average & 20345.335 & 4 & Sangat bagus \\
& Tdown_average & 26349.165 & 4 & Sangat bagus \\
\hline
\end{tabular}

Tabel indeks pengukuran ini dibuat berdasarkan standar dari TIPHON terhadap parameterparameter QoS. Dapat dilihat bahwa kualitas pelayanan jaringan internet berbasis seluler di Kecamatan Sungai Pinang Kota Samarinda dalam kategori seperti pada tabel.

\section{Kesimpulan dan saran}

\subsection{Simpulan}

Penyedia internet service berupaya menjaga kelayakan akses internet dengan menyediakan Quality of Service (QoS) yang bagus pada trafik jaringannya. Analisis spasial data jaringan seluler Kecamatan Sungai Pinang, Kota Samarinda dilakukan dengan Pengukuran untuk mendapatkan data uplink delay/latency, downlink delay/latency, uplink throughput, downlink throughput dan jitter. Dari hasil rata-rata pengukuran dilakukan perhitungan rata-rata dengan menentukan indeks menurut standar TIPHON (Telecommunications and Internet Protocol Harmonization Over Network)

5.2. Saran
a. Menambah titik lokasi pengukuran agar pemetaan jaringan lebih detail dan sesi waktu pengukuran.
b. Menambah banyaknya nilai paket data.
c. Paket data dapat diubah berupa media yang dikirimkan, misalnya gambar, suara atau video.
d. Menambah banyak tes pada setiap nilai paket data pengukuran

\section{Daftar Pustaka}

[1] Apriyana Nana. 2009. Pengembangan Jaringan Data Spasial Nasional (JDSN). Online Bulletin. Edisi November - Desember 2009.http://penataanruang.pu.go.id/bulletin/index.asp. Diakses tanggal 2 Oktober 2015.

[2] BPS. 2015. Statistik Daerah Kecamatan Sungai Pinang. Badan Pusat Statistik Kota Samarinda. Katalog BPS: 1101002.6472. https://samarindakota.bps.go.id

[3] Irwansyah Edy. 2013. Sistem Informasi Geografis: Prinsip Dasar dan Pengembangan Aplikasi. Digibooks. Cetakan 1. Yogyakarta

[4] Gumelar, Dhani. 2007. Data Spasial. IImuKomputer.Com. Komunitas eLearning IImuKomputer.Com. Copyright @ 2003-2007 IlmuKomputer.Com.

[5] Khaeriati, Mifti. 2014. Perangkat Lunak Pengukuran Performansi Jaringan Data Seluler Berbasis Mobil. Teknik Informatika. Universitas Mulawarman. Samarinda

[6] Pandudu, Ady Wahyudi dan Zahir Zainuddin (2011). MoPing: Pengukuran Layanan Paket Data Pada Jaringan Selular. Teknik Informatika. Universitas Hasanuddin. Makassar.

[7] Radjabidfard, Abbas. 2001. SDI Hierarchy, from Local to Global SDI Initiatives. Melbourne, Victoria: Spatial Data Research Group, Departement of Geomatics. The University of Melbourne.

[8] _ 2000a."Spatial Data Infrastructures : Concept, SDI Hierarchy and Future Directions." Melbourne, Victoria: Spatial Data Research Group, Department of Geomatics, The University of Melbourne. 